\title{
GROWTH AND CHARACTERIZATION OF SELF-ASSEMBLED NANOFIBERS
}

\author{
M. E. Salmon ${ }^{*}$, P.E. Russell* and E.B. Troughton Jr.* \\ * - AIF - North Carolina State University, Campus Box 7531, Raleigh, NC 27695, USA \\ ** - Thomas Lord Research Center, Lord Corporation, Box 8012, Cary, NC 27512, USA
}

Self-assembled structures are of increasing interest today due to the rapid progression of micro- and nano- scale engineering applications. In recent years much attention has been placed on understanding the formation and properties of monomolecular thin films, also known as selfassembled monolayers (SAMs), for use as corrosion inhibitors, lubricants, and adhesion promoters[1,2]. Much of the advancement in this field has come from the unprecedented resolution of scanned probe microscopy (SPM), the scanning tunneling microscope (STM) and the atomic force microscope (AFM), invented in the mid to late 1980's.

Rather than coherent films, novel self-assembled nanofibers form over time on evaporated Al thin films when immersed in a solution of $0.1 \mathrm{wt} \%$ methylphosphonic acid (MPA) and absolute ethanol at room temperature [3]. When $\mathrm{Al}$ is deposited onto only a small portion of a substrate, over time, fibers are found on both the initial $\mathrm{Al}$ as well as on areas adjacent to the remaining Al film. By patterning the Al, nanofibers can be created without Al underneath for use in compositional, mechanical and thermal analysis. Figure 1. shows the typical nanofiber growth on $\mathrm{Si}_{3} \mathrm{~N}_{4}$ after immersion for 8 days in solution. Recent advancements in sample preparation have lead to the creation of unsupported nanofibrous membranes grown across $4 \mu \mathrm{m}$ holes in a Al coated ProtoChips, Inc. DuraSiN ${ }^{\mathrm{TM}}$ silicon nitride support meshes. Figure 2 is a Scanning Transmission Electron Microscope (STEM) image of the resulting novel membrane. These results show for the first time the ability to grow unsupported self-assembled nanofabrics from solution that are stable in ambient conditions.

The AFM has proven to be a valuable tool for examining changes in morphology of nanostructures under a variety of environmental conditions. Nanofibers grown on a $\mathrm{Si}_{3} \mathrm{~N}_{4}$ coated $\mathrm{Si}$ substrate, adjacent to a region of evaporated Al, were subjected to in-situ heat treatments in a JEOL JSPM5200 environmental SPM. The sample was heated at each temperature of interest for 30 minutes then cooled and imaged all while continuously under moderate vacuum $\left(1 \times 10^{-7}\right.$ torr $)$. The nanofibers exhibit remarkably high temperature stability as compared to the $100^{\circ} \mathrm{C}$ melting temperature of pure MPA. The nanofibers appear to be stable with no observable change in morphology even after heating to $500 \mathrm{C}$.

In summary, novel fibrous structures are formed on a variety of substrates by immersion of Al metal into a $0.1 \mathrm{wt} \% \mathrm{MPA} /$ Ethanol solution over time. A variety of results including growth techniques as well as thermal, mechanical, electrical, and structural characterization using AFM and other techniques for isolated fibers and unsupported self-assembled nanofabrics will be presented.

[1] - P.E. Laibinis, et al., Science 245 (1989) 845.

[2] - A. Ulman, An Introduction to Ultrathin Films, Academic Press, San Diego, USA (1991).

[3] - Salmon ME, et al., Proceedings of Microscopy and Microanalysis (2002) 845. 


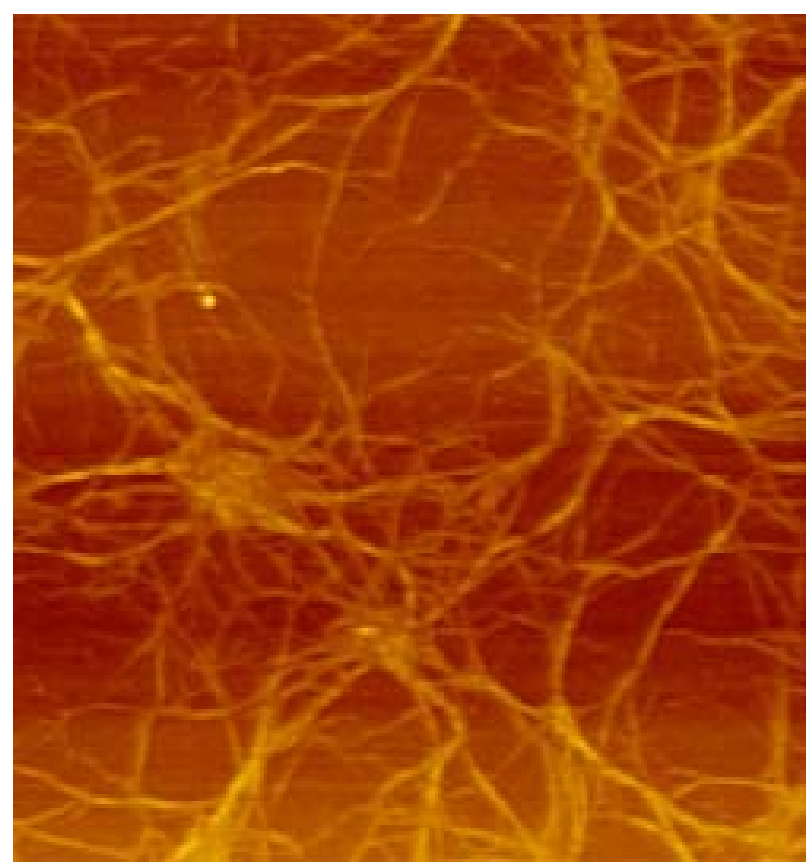

Figure $1.5 \mu \mathrm{m} \times 5 \mu \mathrm{m}$ AFM TappingMode ${ }^{\mathrm{TM}}$ height image, $50 \mathrm{~nm} \mathrm{Z}$ range, showing isolation of individual nanofiber growth on a $\mathrm{Si}_{3} \mathrm{~N}_{4}$ film.

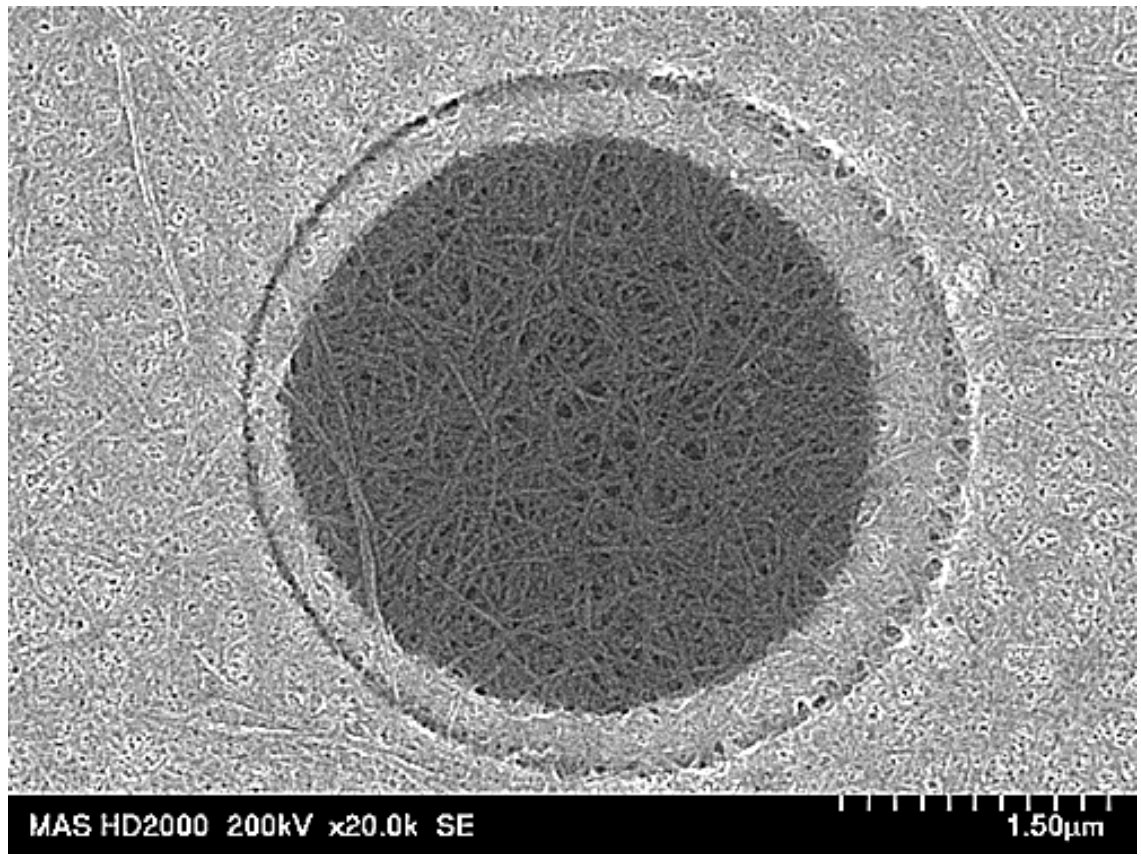

Figure 2. Scanning Transmission Electron Microscope secondary electron image of an unsupported, self-assembled, nanofibrous membrane grown over a $4 \mu \mathrm{m}$ hole in a $\mathrm{Al}$ coated, ProtoChips, Inc. DuraSiN, silicon nitride support Mesh. 